\title{
Three-dimensional microstructures of the intracortical canals in the animal model of osteoporosis
}

\author{
Shin-Hyo Lee ${ }^{1, \star}$, Jeong-Nam Kim ${ }^{2, \star}$, Kang-Jae Shin ${ }^{3}$, Ki-Seok Koh ${ }^{1}$, Wu-Chul Song ${ }^{1}$ \\ ${ }^{1}$ Department of Anatomy, Research Institute of Medical Science, Konkuk University School of Medicine, Seoul, ${ }^{2}$ Department of Biomedical Laboratory \\ Science, Kyungnam College of Information \& Technology, Busan, ${ }^{3}$ Department of Anatomy and Cell Biology, Dong-A University School of Medicine, \\ Busan, Korea
}

\begin{abstract}
Osteoporosis is a major disease in aged women, increasing the risk for fractures accompanied by changes in the microarchitecture. The aim of this study was to investigate the three-dimensional (3D) histomorphology of femur diaphysis in the animal model for postmenopausal osteoporosis. The cortical bone of femur diaphysis of the rat was serially sectioned at a thickness of $5 \mu \mathrm{m}$ and evaluated age-associated changes of the intracortical (osteonal) canal networks three-dimensionally. Cortical microstructures of 10 -month old rats were not affected by ovariectomy. Intracortical canal networks were radial toward endosteal aspect and frequently interconnected across the neighboring canals with short arciform and irregular canals reminiscent for resorption spaces in ovarectomized 16-month old rats, contrary to intact canals in 16-month old control rat. Increased proportion of the periosteal circumference lamella and deformed endosteal regions with rare cortical canals hampered reconstructive histomorphology in ovarectomized rats of 26 month age. We have shown that 3D reconstruction of rat femur of the aged model over 16-month old is suitable methods that evaluate and microstructural change of the intracortical canals and cortical bone porosity by estrogen depletion.
\end{abstract}

Key words: Intracortical canal, Femur, Three-dimensional reconstruction, Osteoporosis, Ovariectomy

Received August 28, 2019; Revised November 20, 2019; Accepted December 18, 2019

\section{Introduction}

Osteoporosis is a major disease of aging, characterized by low bone mass and microstructural deterioration of bone that lead to increased susceptibility to fractures [1]. Osteoporosis has complex pathogenesis and multifactorial etiology and the main risk factors are represented by the menopausal hormonal changes [2-4].

\footnotetext{
Corresponding author:

Wu-Chul Song (iD

Department of Anatomy, Research Institute of Medical Science, Konkuk University School of Medicine, Seoul 05029, Korea

E-mail: anatomy@kku.ac.kr
}

*These authors contributed equally to this work.
Although osteoporosis-related fracture risk is clinically assessed by a decrease of overall bone mineral density, the mechanical properties of bone are determined not only by bone mass but also by bone quality. An important parameter of bone quality is the ability of the material to withstand microdamage which is greatly affected by bone microarchitecture [5-9]. Many studies have focused on trabecular bone alterations in pathologic conditions owing to their earlier response of bone loss than cortical bone in animal models and human [10-17]. However, cortical bone globally represents $80 \%$ of the skeleton bone mass and therefore contributes indispensably to mechanical bone strength [18].

The cylindrical structural units that comprise most cortical bone are osteons lie parallel with each other in lone bones. Adjacent osteons may encroach on one another dur-

\section{Copyright () 2020. Anatomy \& Cell Biology}

This is an Open Access article distributed under the terms of the Creative Commons Attribution Non-Commercial License (http://creativecommons.org/licenses/by-nc/4.0/) which permits unrestricted non-commercial use, distribution, and reproduction in any medium, provided the original work is properly cited. 
ing successive periods of bone remodeling [19]. Deterioration of bone microarchitectures such as cortical porosity and disorganization of osteonal canals could influence to maintenance of bone homeostasis and mechanical properties of appendicular bones [1, 20-22].

This study aimed to compare fine details of bone microstructural morphology of the cortical bone between the osteoporosis and control (CON) groups using three-dimensional (3D) reconstruction. A histomorphology following the osteonal canal networks across the lifespan of the animal model may facilitate understanding of the etiology and pathophysiology of osteoporosis in postmenopausal women.

\section{Materials and Methods}

\section{Subjects}

The study was carried out on the femurs of eighteen female Sprague-Dawley rats. At the age of 9 weeks weighing approximately $190 \mathrm{~g}$, animals were divided into two groups: CON and ovariectomized (OVX) (Fig. 1A). OVX rats were anesthetized with a mixture of ketamine $(90 \mathrm{mg} / \mathrm{kg})$ and xylazine $(10 \mathrm{mg} / \mathrm{kg})$ by intraperitoneal route. Ovariectomy was preceded by two dorsolateral incisions. CON and OVX rats maintained in a controlled environment with a room temperature of $22^{\circ} \mathrm{C} \pm 4^{\circ} \mathrm{C}$, a relative humidity of $55 \% \pm 20 \%$, and a 12-hour light and dark cycle in the animal facility of the Medical School of Konkuk University.

Animals at 8, 10, 16, and 26-month old were sacrificed spatially to clarify the morphologic dynamics of the femoral cortex under influence of ovariectomy. Animals care protocol was reviewed by the Institutional Animal Care and Use Committee at Konkuk University (IACUC-KU09054).

\section{Histological evaluation}

Excised femurs were dissected from soft tissues and decalcified in 5\%-formalin. The femurs were cut with a blade in a plane perpendicular to the longitudinal axis of the diaphysis. The specimens were trimmed to $5 \mathrm{~mm}^{3}$ sized pieces to make them easier to handle and to facilitate the acquisition of images during fixation. The anterolateral region of the middiaphyseal parts was decalcified and embedded in a block of paraffin (Fig. 1B). Serial sections were cut in the plane per-
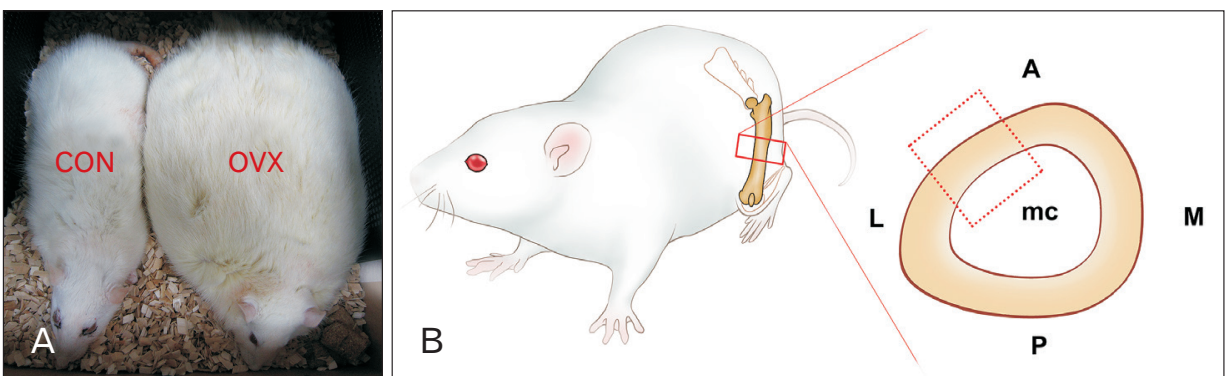

Fig. 1. Specimens subjected to histomorphologic evaluation. (A) Significant weight gain of OVX group compared to the CON rat. (B) Scheme of the preparation of rat femur. The section planes for anterolateral aspect of a femur (dotted box) and the references for mid-diaphysis (lined box). A, anterior; CON, control; L, lateral; M, medial; mc, marrow cavity; OVX, ovariectomized; P, posterior.
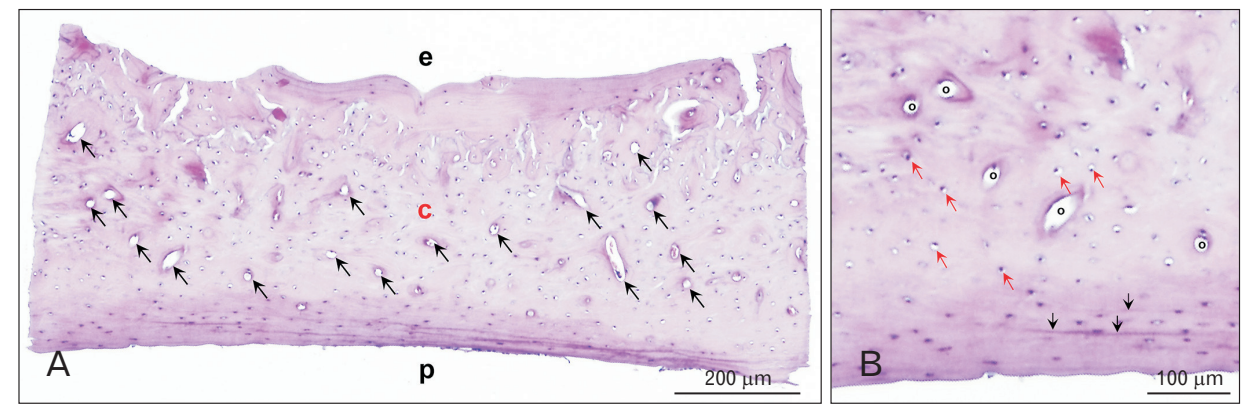

Fig. 2. A histological section of 10 -month old control rat. (A) Osteons (black arrows) were concentrated in the mid-cortical area (H\&E, $\times 200)$. (B) Magnification of osteon with lacuna (red arrows) (H\&E, $\times 100)$. Periosteal circumference lamella (black arrows). c, mid-cortical area; e, endothelial aspect; o, osteon; p, periosteal aspect. 
pendicular to the long axis of the bone at a thickness of $5 \mu \mathrm{m}$ and stained with Hematoxylin and Eosin (Fig. 2).

\section{Three-dimensional reconstruction}

All of the stained cross sections were photographed using a 2,048 $\times 1,536$-pixel digital CCD camera (DP70; Olympus, Tokyo, Japan). The intracortical (osteonal) canals of the femur were segmented manually and reconstructed at 50$\mu \mathrm{m}$ intervals by 'Reconstruct' software (this software can be downloaded from http://synapseweb.clm.utexas.edu/software-0; accessed April 1, 2019).

\section{Results}

Cortical bone of diaphysis of rat femur composed of the endosteal circumference lamella toward the marrow cavity, a mid-cortical area abundant with vascular canals, and the periosteal circumference lamella under the periosteum (Fig. 2A). There was no obvious histological difference between CON and OVX groups under 16 month of age (8 and 10-month age; data not shown). Intracortical (osteonal) canal networks of rat cortical bone could be described as the osteon deficient in complete concentric structures, but accom-

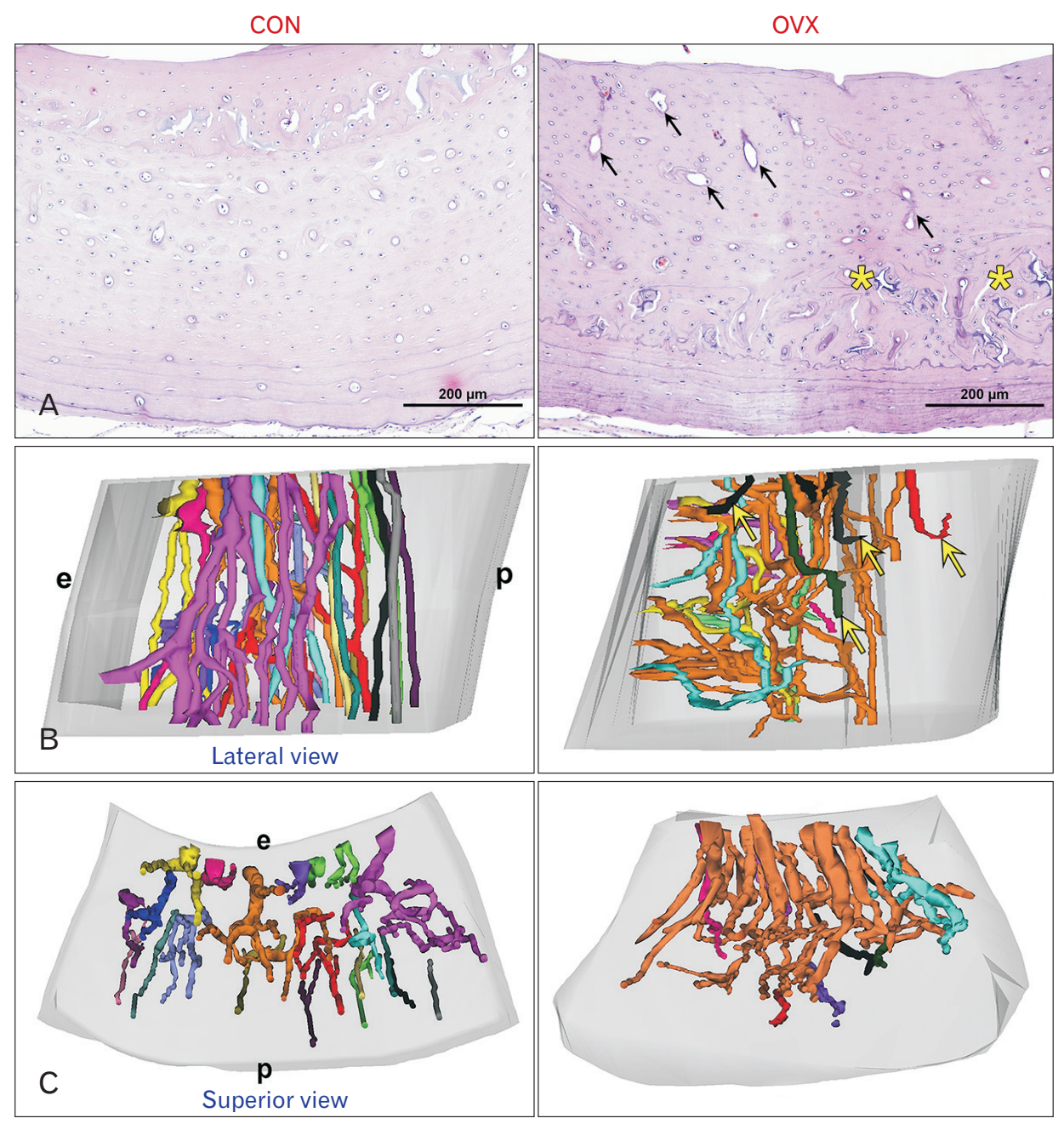

Fig. 3. Changes of cortical microstructures in 16 months' rats. (A) Cross section of the rat femur stained with hematoxylin and eosin. Compared to a CON rat, oval osteons toward endosteal aspect and coarse compact cancellous bone with unorganized tissues (yellow asterisks) are evident in an OVX rat $(\mathrm{H} \& \mathrm{E}, \times 200)$. (B) Lateral views of the 3-dimensional structure of the cortical canal networks. Cortical canals are pre-dominantly separated and longitudinal in the entire area in a CON rat. In an OVX rat, radial canals adjacent to the endosteal region were convoluted and closely connected each other or disconnected (yellow arrows), while that of the periosteal region was straight. (C) Superior views of the 3-dimensional structure. The canal openings faced the marrow cavity much more than the periosteum. Osteonal canals with dichotomous branching oriented obliquely toward the endosteal aspect. All images have the same magnification. CON, control; e, endothelial aspect; OVX, ovariectomized; p, periosteal aspect. 
panied abundant lacunae (Fig. 2B).

In a $\mathrm{CON}$ rat at 16 months' age, the periosteal circumference lamella increased the thickness and resorption cavities appeared at the medial mid-cortical areas. However, intact endosteal surface and round or oval vascular canals retained. In an OVX rat at 16 months' age, oblique osteons toward the marrow cavity and the periosteal bone disposition with coarse unorganized tissues were evident (Fig. 3A).

All tubular structures both pre-existing osteonal canals and polycyclic pits unknown were subjected to $3 \mathrm{D}$ reconstruction procedures. In a CON rat at 16 months' age, osteonal canals with bifurcation patterns were generally oriented along the longitudinal axis of the diaphysis and separated independently. In an OVX rat at 16 months' age, radially oriented canals toward the endosteal aspect occupied endosteal aspect of the mid-cortex area with local irregularities in canal orientations (Fig. 3B). Osteonal canals on the endosteal side were wider and convoluted, more intricately interconnected resulted in increased cortical porosity in the endosteal cortex (Fig. 3C).

A thickness of the cortical bone was reduced in both CON and the OVX group at 26 months' age. In an OVX rat, the cortical bone exhibited an irregular morphology that obliterated the osteonal canal morphology and had an enlarged resorption space in the endosteal surface. A cortical thinning by the endosteal erosion, trabecularization of the endosteal aspect of the cortical volumes, and a thickened periosteal circumference lamella preclude 3D reconstruction (Fig. 4).

\section{Discussion}

Osteoporosis is one of the most common disorders in postmenopausal women, increasing the risk for bone fractures accompanied by changes in the microarchitecture [2]. The nature of microdamage accumulations under fatigue loading and its location in the bone matrix plays a role in determining the age-related fragility of cortical bone [6]. Particular emphasis is placed on the role of estrogen in the signaling pathway related to the biological remodeling process through resorption/regeneration contributing to bone strength [3, 16, 23-25]. Therefore, the OVX rat is a widely used preclinical model approved by the Food and Drug Administration that emulates the important clinical feature of the postmenopausal human skeleton $[12,14,15]$. The bone loss in postmenopausal women and OVX rats are associated with elevated bone turnover and continuous change to cortical microstructures in long bones by the excavation and refilling of cavities during the lifetime [26-28].

A better understanding of the relation between cortical bone microstructures and bone strength might be relevant for evaluating the fracture risk of osteoporotic patients, particularly in the appendicular skeleton to allow efficient locomotion of the body [18, 29]. Kim et al. [30], demonstrated the actual osteonal canal network using 3D reconstruction in adult rats. The present study evaluated the intracortical canal networks of anterolateral femur of entire volume, subjected to aged groups by the same methods. 16 month old rats showed remarkable changes in the histological and $3 \mathrm{D}$ cortical matrix by ovariectomy. A 3D images of 16 -month old OVX rats suggested by the present study showed osteo-

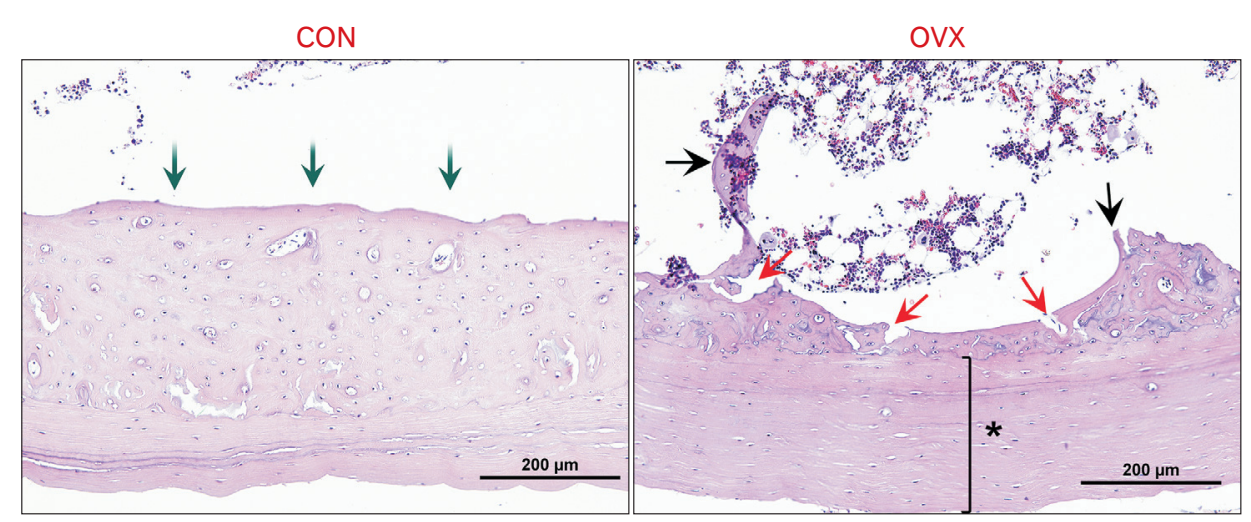

Fig. 4. An age-related cortical bone loss coupled with the expansion of the medullary cavity and thickened periosteal circumference lamella in rats of 26 -month old $(\mathrm{H} \& \mathrm{E}, \times 200)$. Reduced volume of mid-cortical area in a CON rat (green arrows). Disorganized mid-cortical area and irregular endosteal surface with resorption cavities (red arrows), trabeculae (black arrows), and thickened periosteal circumference lamella (asterisk) in an OVX rat. CON, control; OVX, ovariectomized. 
porosis progresses which are defined as the overall thickness of cortical bone decreases and highly interconnected and disorganized cortical canals in the endosteal aspect (Fig. 3B, C). The regional difference of intracortical canal orientations of the femur may have been a result of the regional variation in strain mode loaded to bone $[22,31,32]$.

Osteon aligns themselves parallel to the loading direction corresponds to habitual principal stress direction aimed at improving bone's ability to endure the loading [33]. Several studies proposed that the prevailing oblique orientation of the secondary osteon correlate with bending to the medial side and to an external rotation torsional loading causes more circumferential canals, whereas compression and tension resulted in more longitudinal canals [21, 34-36]. Cortical mass at the long bone of rats are known to continues expansion until about 10-12 month old, and a decrease in bone strength was not apparent in femoral mid-diaphysis until 15-month old post ovariectomy [12]. The orientation of the cortical canal network in a bone is the consequence of a complex interaction between the growth rate of that bone and the functional loading environment [37].

In the present study, the periosteal bone formation in aged OVX rats showed thickened periosteal circumference lamella with endosteal erosion (Figs. 4, 5). In the cortical bone, the aging causes the endocortical resorption leading to cortical thinning and marrow cavity expansion, and accumulation of the periosteal lamella deficient in lacuna $[3,7]$. This histomorphology corresponds with previous reports that bone loss in aging occurs at endosteal surfaces adjacent to the marrow cavity contrasted to extended periosteal region resistant to remodeling $[5,24,38]$. Osteoporotic cortical bones might be vulnerable to absorb sudden torsional loading from the relative vulnerability of the medial cortical region.

The limitations of the present study are that the laboratory rodents have been considered to suitability as models for the cortical bone turnover process because of a lack of Haversian remodeling activity [5]. Although Haversian systems in rodents have been known to be incomplete owing to the morphology of interstitial lamella [39-44], elderly rats over 16 months of age developed the resorption cavity and irregular osteonal canals with vascular endothelium in the femoral cortex in the present study. In the mature established vasculature, the endothelium plays a pivotal role in the maintenance of homeostasis of the surrounding tissue providing the communicative network to neighbouring tissues to respond to requirements as needed [45]. Therefore, we suggested that the elderly OVX model over 16 months' age could be suitable methods to evaluate the cortical porosity via the morphologic dynamics of intracortical canals.

Our results based on the histomorphology of an appendicular bone could improve the knowledge of the basis for the study of the aging and involution of the cortical bone in osteoporosis and other diseases characterized by bone loss. Comprehensive analysis of the large population of elderly OVX rats would be necessary to evaluate microstructural variation at intraspecific levels, the mechanobiological response of the cortical canal networks, and the effect of estrogen deficiency in osteoporosis models.
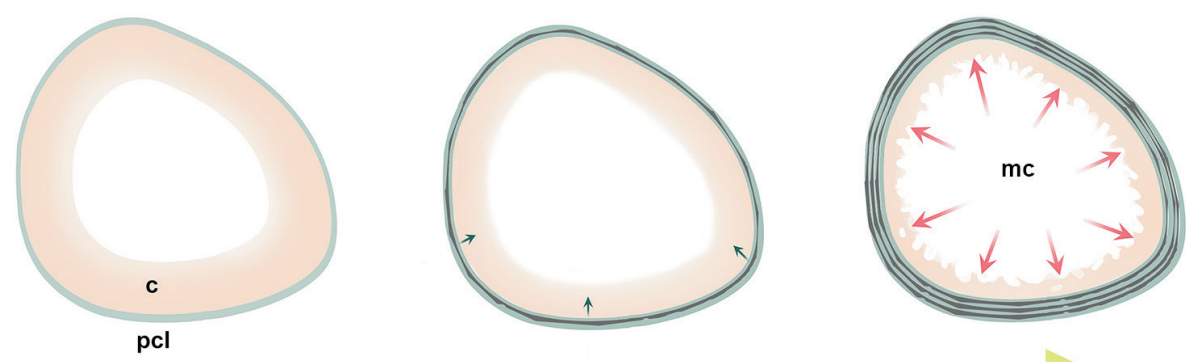

Estrogen depletion

Fig. 5. Scheme of cross sections of femur diaphysis with aging and estrogen depletion. Decreased volume of the cortical bone (yellow) and the thickened periosteal circumference lamella (green) with aging resulted in the expansion of the marrow cavity and reduced dimension of the cortical stroma. Endosteal erosion of mid-cortical area hardened with the ovariectomy and menopause. c, mid-cortical area; mc, marrow cavity; pcl, periosteal circumference lamella. 


\section{ORCID}

Shin-Hyo Lee: https://orcid.org/0000-0001-7031-7722 Jeong-Nam Kim: https://orcid.org/0000-0002-6318-8317

Kang-Jae Shin: https://orcid.org/0000-0001-8703-9220

Ki-Seok Koh: https://orcid.org/0000-0003-2861-4031

Wu-Chul Song: https://orcid.org/0000-0001-9678-1830

\section{Author Contributions}

Conceptualization: JNK, WCS. Data acquisition: JNK, KJS. Data analysis or interpretation: SHL, WCS. Drafting of the manuscript: SHL. Critical revision of the manuscript: WCS, KSK. Approval of the final version of the manuscript: all authors.

\section{Conflicts of Interest}

No potential conflict of interest relevant to this article was reported.

\section{References}

1. Wang J, Stein EM, Zhou B, Nishiyama KK, Yu YE, Shane E, Guo XE. Deterioration of trabecular plate-rod and cortical microarchitecture and reduced bone stiffness at distal radius and tibia in postmenopausal women with vertebral fractures. Bone 2016;88:39-46.

2. Pavel OR, Popescu M, Novac L, Mogoantă L, Pavel LP, Vicaş RM, Trăistaru MR. Postmenopausal osteoporosis - clinical, biological and histopathological aspects. Rom J Morphol Embryol 2016;57:121-30.

3. Hemmatian H, Bakker AD, Klein-Nulend J, van Lenthe GH. Aging, osteocytes, and mechanotransduction. Curr Osteoporos Rep 2017;15:401-11.

4. Britz HM, Thomas CD, Clement JG, Cooper DM. The relation of femoral osteon geometry to age, sex, height and weight. Bone 2009;45:77-83.

5. Bentolila V, Boyce TM, Fyhrie DP, Drumb R, Skerry TM, Schaffler MB. Intracortical remodeling in adult rat long bones after fatigue loading. Bone 1998;23:275-81.

6. Kennedy OD, Brennan O, Mauer P, Rackard SM, O'Brien FJ, Taylor D, Lee TC. The effects of increased intracortical remodeling on microcrack behaviour in compact bone. Bone 2008;43: 889-93.

7. Lee KC, Maxwell A, Lanyon LE. Validation of a technique for studying functional adaptation of the mouse ulna in response to mechanical loading. Bone 2002;31:407-12.

8. De Souza RL, Matsuura M, Eckstein F, Rawlinson SC, Lanyon LE, Pitsillides AA. Non-invasive axial loading of mouse tibiae increases cortical bone formation and modifies trabecular organization: a new model to study cortical and cancellous compartments in a single loaded element. Bone 2005;37:810-8.

9. Popp KL, Hughes JM, Martinez-Betancourt A, Scott M, Turkington V, Caksa S, Guerriere KI, Ackerman KE, Xu C, Unnikrishnan G, Reifman J, Bouxsein ML. Bone mass, microarchitecture and strength are influenced by race/ethnicity in young adult men and women. Bone 2017;103:200-8.

10. Carter DR, Orr TE, Fyhrie DP. Relationships between loading history and femoral cancellous bone architecture. J Biomech 1989;22:231-44.

11. Ishihara A, Sasaki T, Debari K, Furuya R, Kawawa T, Ramamurthy NS, Golub LM. Effects of ovariectomy on bone morphology in maxillae of mature rats. J Electron Microsc (Tokyo) 1999;48:465-9.

12. Jee WS, Yao W. Overview: animal models of osteopenia and osteoporosis. J Musculoskelet Neuronal Interact 2001;1:193-207.

13. Walker MD, Liu XS, Stein E, Zhou B, Bezati E, McMahon DJ, Udesky J, Liu G, Shane E, Guo XE, Bilezikian JP. Differences in bone microarchitecture between postmenopausal ChineseAmerican and white women. J Bone Miner Res 2011;26:1392-8.

14. Johnston BD, Ward WE. The ovariectomized rat as a model for studying alveolar bone loss in postmenopausal women. Biomed Res Int 2015;2015:635023.

15. Hsu PY, Tsai MT, Wang SP, Chen YJ, Wu J, Hsu JT. Cortical bone morphological and trabecular bone microarchitectural changes in the mandible and femoral neck of ovariectomized rats. PLoS One 2016;11:e0154367.

16. Farooq S, Leussink S, Sparrow LM, Marchini M, Britz HM, Manske SL, Rolian C. Cortical and trabecular morphology is altered in the limb bones of mice artificially selected for faster skeletal growth. Sci Rep 2017;7:10527.

17. Popp KL, Xu C, Yuan A, Hughes JM, Unnikrishnan G, Reifman J, Bouxsein ML. Trabecular microstructure is influenced by race and sex in Black and White young adults. Osteoporos Int 2019;30:201-9.

18. Basillais A, Bensamoun S, Chappard C, Brunet-Imbault B, Lemineur G, Ilharreborde B, Ho Ba Tho MC, Benhamou CL. Three-dimensional characterization of cortical bone microstructure by microcomputed tomography: validation with ultrasonic and microscopic measurements. J Orthop Sci 2007;12: 141-8.

19. Standring S. Gray's anatomy: the anatomical basis of clinical practice. 41th ed. Amsterdam; Elsevier Health Sciences, 2016. p. 88.

20. Cooper DM, Thomas CD, Clement JG, Turinsky AL, Sensen CW, Hallgrímsson B. Age-dependent change in the 3D structure of cortical porosity at the human femoral midshaft. Bone 2007;40:957-65.

21. Britz HM, Jokihaara J, Leppänen OV, Järvinen TL, Cooper DM. The effects of immobilization on vascular canal orientation in rat cortical bone. J Anat 2012;220:67-76.

22. Harrison KD, Cooper DM. Modalities for visualization of cortical bone remodeling: the past, present, and future. Front 
Endocrinol (Lausanne) 2015;6:122.

23. Klein-Nulend J, van Oers RF, Bakker AD, Bacabac RG. Bone cell mechanosensitivity, estrogen deficiency, and osteoporosis. J Biomech 2015;48:855-65.

24. Danielsen CC, Mosekilde L, Svenstrup B. Cortical bone mass, composition, and mechanical properties in female rats in relation to age, long-term ovariectomy, and estrogen substitution. Calcif Tissue Int 1993;52:26-33.

25. Sugiyama T, Oda H. Osteoporosis therapy: bone modeling during growth and aging. Front Endocrinol (Lausanne) 2017;8:46.

26. Pazzaglia UE, Congiu T, Pienazza A, Zakaria M, Gnecchi M, Dell'orbo C. Morphometric analysis of osteonal architecture in bones from healthy young human male subjects using scanning electron microscopy. J Anat 2013;223:242-54.

27. Westerlind KC, Wronski TJ, Ritman EL, Luo ZP, An KN, Bell $\mathrm{NH}$, Turner RT. Estrogen regulates the rate of bone turnover but bone balance in ovariectomized rats is modulated by prevailing mechanical strain. Proc Natl Acad Sci U S A 1997;94: 4199-204.

28. Andreasen CM, Delaisse JM, van der Eerden BCJ, van Leeuwen JPTM, Ding M, Andersen TL. Understanding age-induced cortical porosity in women: is a negative BMU balance in quiescent osteons a major contributor? Bone 2018;117:70-82.

29. Leppänen O, Sievänen H, Jokihaara J, Pajamäki I, Järvinen TL. Three-point bending of rat femur in the mediolateral direction: introduction and validation of a novel biomechanical testing protocol. J Bone Miner Res 2006;21:1231-7.

30. Kim JN, Lee JY, Shin KJ, Gil YC, Koh KS, Song WC. Haversian system of compact bone and comparison between endosteal and periosteal sides using three-dimensional reconstruction in rat. Anat Cell Biol 2015;48:258-61.

31. van Hove RP, Nolte PA, Vatsa A, Semeins CM, Salmon PL, Smit $\mathrm{TH}$, Klein-Nulend J. Osteocyte morphology in human tibiae of different bone pathologies with different bone mineral densityis there a role for mechanosensing? Bone 2009;45:321-9.

32. van Oers RF, Wang H, Bacabac RG. Osteocyte shape and mechanical loading. Curr Osteoporos Rep 2015;13:61-6.

33. Hert J, Fiala P, Petrtýl M. Osteon orientation of the diaphysis of the long bones in man. Bone 1994;15:269-77.

34. Martin RB. Targeted bone remodeling involves BMU steering as well as activation. Bone 2007;40:1574-80.

35. Pazzaglia UE, Congiu T, Raspanti M, Ranchetti F, Quacci D. Anatomy of the intracortical canal system: scanning electron microscopy study in rabbit femur. Clin Orthop Relat Res 2009; 467:2446-56.

36. Pazzaglia UE, Congiu T, Marchese M, Zarattini G. Structural pattern and functional correlations of the long bone diaphyses intracortical vascular system: investigation carried out with China ink perfusion and multiplanar analysis in the rabbit femur. Microvasc Res 2011;82:58-65.

37. Pratt IV, Cooper DML. The effect of growth rate on the threedimensional orientation of vascular canals in the cortical bone of broiler chickens. J Anat 2018;233:531-41.

38. Aaron JE. Periosteal Sharpey's fibers: a novel bone matrix regulatory system? Front Endocrinol (Lausanne) 2012;3:98.

39. Jowsey J. Studies of Haversian systems in man and some animals. J Anat 1966;100(Pt 4):857-64.

40. Singh IJ, Tonna EA, Gandel CP. A comparative histological study of mammalian bone. J Morphol 1974;144:421-37.

41. Cvetkovic VJ, Najman SJ, Rajkovic JS, Zabar ALj, Vasiljevic PJ, Djordjevic LjB, Trajanovic MD. A comparison of the microarchitecture of lower limb long bones between some animal models and humans: a review. Vet Med 2013;58:339-51.

42. Montoya-Sanhueza G, Chinsamy A. Long bone histology of the subterranean rodent Bathyergus suillus (Bathyergidae): ontogenetic pattern of cortical bone thickening. J Anat 2017;230:20333.

43. Shipov A, Zaslansky P, Riesemeier H, Segev G, Atkins A, Shahar R. Unremodeled endochondral bone is a major architectural component of the cortical bone of the rat (Rattus norvegicus). J Struct Biol 2013;183:132-40.

44. Skedros JG, Sorenson SM, Jenson NH. Are distributions of secondary osteon variants useful for interpreting load history in mammalian bones? Cells Tissues Organs 2007;185:285-307.

45. Kanczler JM, Oreffo RO. Osteogenesis and angiogenesis: the potential for engineering bone. Eur Cell Mater 2008;15:100-14. 